Open Access

\title{
Intestinal parasitic infections among children under five years of age presenting with diarrhoeal diseases to two public health facilities in Hawassa, South Ethiopia
}

\author{
Getamesay Mulatu', Ahmed Zeynudin², Endalew Zemene ${ }^{2 *}$, Serkadis Debalke² and Getenet Beyene ${ }^{2}$
}

\begin{abstract}
Background: Diarrhoea is the leading cause of morbidity and mortality in children under 5 years of age in developing countries, including Ethiopia. It is caused by a wide range of pathogens, including parasites, bacteria and viruses. The aim of this study was to determine the prevalence of infection with intestinal parasites (IPS) (and types) among children under 5 years of age with diarrhoeal diseases.

Methods: A cross-sectional study was conducted at Adare Hospital and Millennium Health Centre, both located in Hawassa, South Ethiopia, from June 6 to October 28, 2011. Children under 5 years of age with diarrhoea who visited these health facilities during the study period were included in the study. Data relating to demography and risk factors associated with intestinal parasitic infections (IPIs) were gathered using a structured questionnaire. Single, fresh stool specimens were examined for IPs using the direct wet mount examination, followed by Ziehl-Neelsen staining of formol-ether concentrated samples, as per standard procedures. Data were analysed using SPSS Statistics 20 software.

Results: A total of 158 children ( $51.3 \%$ male and $48.7 \%$ female) participated in the study. Overall, the prevalence of IPs was $26.6 \%$ (42/158). Two species of IPs were detected in six children (3.8 \%). Entamoeba histolytica/dispar/ moshkovskii was the predominant parasite identified (11.4\%), followed by Giardia duodenalis (7.0 \%). The multivariable analysis revealed that the age group $\geq 24$ months was significantly associated ( $A O R=0.221$, $95 \% \mathrm{Cl}$ : 0.085-0.576) with prevalence of IPIs.

Conclusion: This study found that intestinal parasites are common among children with diarrheal diseases. The most frequently detected species was E. histolytica/dispar/moshkovskii. Health information about how to prevent diarrheal diseases in general and IPIs in particular should be provided to parents of young children.
\end{abstract}

Keywords: Diarrhoea, Intestinal parasites, Children under 5 years, Hawassa, Ethiopia

\section{Multilingual abstracts}

Please see Additional file 1 for translations of the abstract into the six official working languages of the United Nations.

\section{Background}

Globally, an estimated 1.7 billion cases of diarrhoeal disease occur each year [1]. Diarrhoea is particularly

\footnotetext{
* Correspondence: endalew.zemene@ju.edu.et

${ }^{2}$ Department of Medical Laboratory Sciences and Pathology, College of

Health Sciences, Jimma University, Jimma, Ethiopia

Full list of author information is available at the end of the article
}

devastating for children, and remains one of the leading causes of morbidity and mortality in children under 5 years of age. Nearly one in five child deaths is due to diarrhoea [2-4] - an estimated 760,000 children die of diarrhoea annually [1].

According to the World Health Organization (WHO), diarrhoea is defined as having loose or watery stools at least three times per day, or more frequently than normal for an individual [2]. It is a common symptom of gastrointestinal infections caused by a wide range of pathogens including parasites, bacteria and viruses. In developing countries, diarrhoea is more commonly 
caused by intestinal parasites (IPs) and bacterial pathogens than by viruses [5].

Intestinal parasitic infections (IPIs) are the most common infections among children in developing countries. Giardia duodenalis (G. duodenalis), Cryptosporidium parvum (C. parvum) and Entamoeba histolytica (E. histolytica) are the most common protozoan parasites that cause acute diarrhoeal illnesses in children [5]. The main clinical manifestation of infections with IPs is diarrhoea, with abdominal cramping, vomiting, flatulence and weight loss also being common symptoms. The symptoms can be severe in younger children, as well as in undernourished and immunocompromised patients. Besides protozoan parasites, intestinal helminthic infections are also a huge burden in developing countries, including Ethiopia [6-8]. Intestinal schistosomiasis and soil-transmitted helminths (STHs) are common among school children and preschool children in the country [9-11].

Ethiopia is a developing country in sub-Saharan Africa, where diarrhoea is a significant health problem in children under 5 years of age [12]. In a national survey conducted in 2011, $13 \%$ of children under 5 years of age were reported to have had diarrhoea within two weeks of undertaking the survey, with wide variations among regions [13]. Diarrhoea is a common problem in children in the Southern Nations, Nationalities and People's Region (SNNPR) of Ethiopia. The bacterial pathogens Salmonella, Shigella and Campylobacter, and the IPs E. histolytica and G. duodenalis are the common causes of diarrhoea in developing countries [14-16]. The Cryptosporidium species, Isospora (Cystoisospora) belli and Cyclospora cayetanensis commonly cause diarrhoea in immunocompromised patients [17]. Although bacterial etiologies of diarrhoea in children under 5 years of age in SNNPR has recently been reported [14], the burden of IPs on young children with diarrheal diseases in the region has not yet been investigated. Therefore, this study aimed to determine the prevalence of infection with IPs in children under 5 years of age with diarrhoeal diseases.

\section{Methods}

\section{Study setting}

This study was conducted from June 6 to October 28, 2011 in two public health facilities, namely Adare Hospital and Millennium Health Centre, in the town of Hawassa, South Ethiopia.

An estimated 250 to 300 patients visit Adare Hospital daily. The hospital provides various services, including follow-up for chronic illnesses, family planning, maternity services, emergency and inpatient services, and surgery, among others. Millennium Health Centre sees 100 to 150 patients daily. All services provided by the hospital are also available at the health centre, except for inpatient services and surgery.

Hawassa is the capital of Sidama Zone, located in the SNNPR of Ethiopia (see Fig. 1). The town is located around $270 \mathrm{~km}$ south of Addis Ababa, at an average altitude of 1,708 m above sea level. In 2011 (the study year), an estimated 150,000 people lived in Hawassa.

\section{Study participants and data collection}

A total of 158 children aged three to 59 months presenting to the study health facilities with diarrhoea (at least three loose or watery bowel movements per day), whose parents/guardians gave consent to take part in the study, were included. Seventy-one children $(44.9 \%)$ were from Millennium Health Centre and 87 (55.1\%) were from Adare Hospital. The age groups of the participating children from the two health facilities were comparable.

An attending clinician collected data relating to demography and factors associated with IPIs using a pretested questionnaire. The questionnaire was first developed in English and then translated into Amharic. The children's parents/guardians provided the socio-demographic and clinical data. In addition to the questionnaire, a stool specimen from each participating child was collected and examined for IPs.

Children who were on antiparasitic treatments and whose parents did not consent to participate in the study had to be excluded from the study. However, none of the children were on antiparasitic treatments prior to diagnosis and all parents/guardians consented to take part in the study. Hence, as all children fulfilled the inclusion criteria, no child who presented to the two health facilities with diarrhoea during the study period was excluded from the study.

\section{Stool specimen collection and processing}

Single, fresh stool specimens were collected from study participants in clean, labelled stool cups and investigated as follows: First, direct wet mount of the fresh stool samples was microscopically examined to detect vegetative and other forms of IPs at 100x and 400x magnifications. In the direct wet mount processing, a small amount of the stool was mixed with a drop of physiological saline using an applicator stick, covered with a cover slip and examined under a microscope. Second, formol-ether concentrated specimens that were stained using the modified Ziehl-Neelsen method were examined at 1,000x magnification for detection of protozoan oocysts, namely Cryptosporidium, Cyclospora and Isospora. Established procedures for the direct wet mount examination, formol-ether oocyst concentration and modified Ziehl-Neelsen staining method were followed [18]. An experienced laboratory technologist processed and examined the specimens. The entire negative specimens and $10 \%$ of 


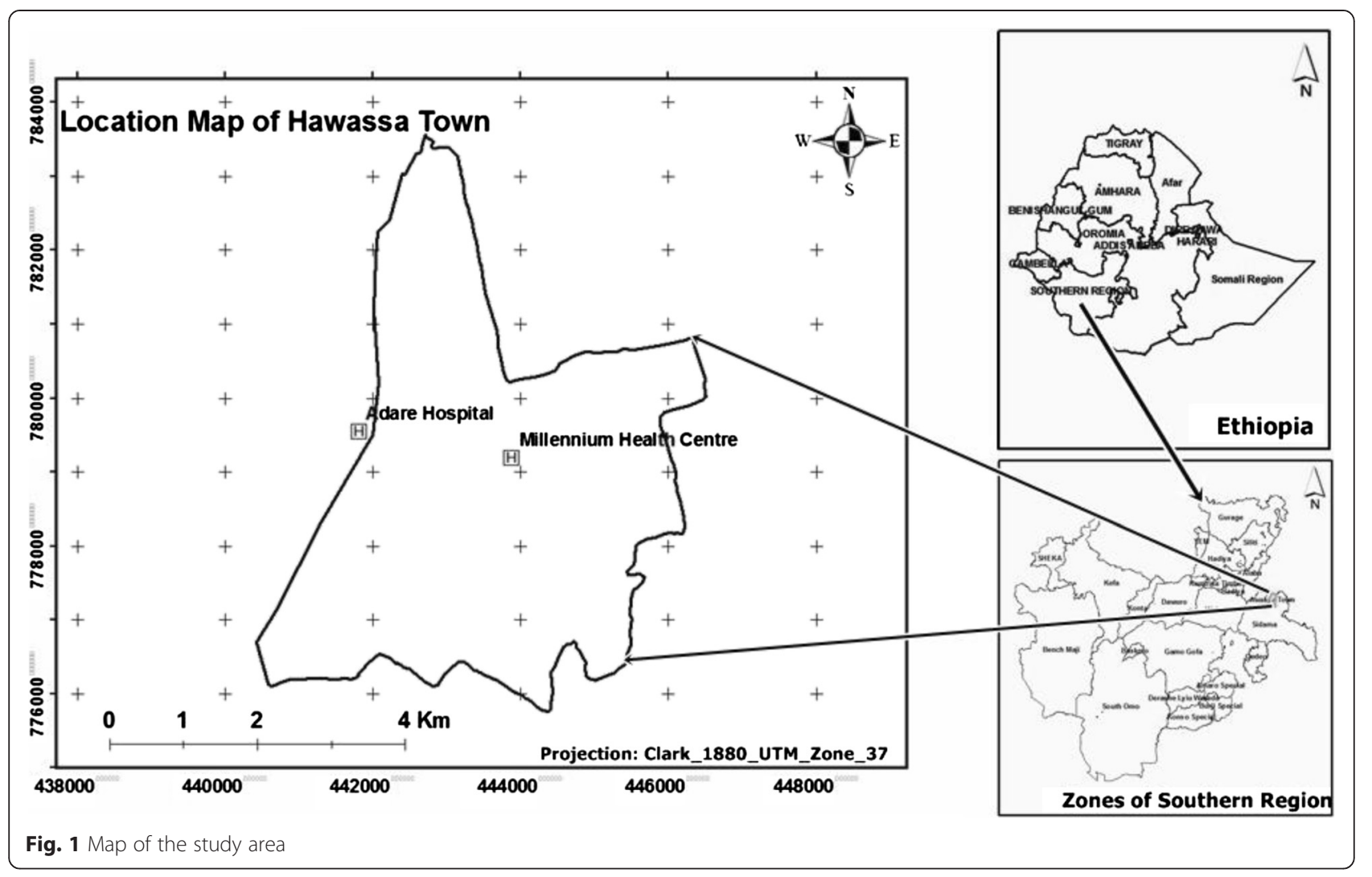

the positive slides were double checked by another blinded technologist.

\section{Data analysis}

Data were entered into a computer, cleaned and analysed using SPSS Statistics 20 software package. Descriptive statistics were used to summarise the socio-demographic characteristics of the study participants. Bivariate and multivariable analyses were conducted to assess the risk factors associated with IPIs among the participating children. $P$-values $<0.05$ were considered significant.

\section{Ethical considerations}

Ethical clearance was obtained from the Ethical Review Committee of Jimma University. Permission was obtained from Regional Health Bureau, Adare Hospital and Millennium Health Centre. Written consent was obtained from the parents/guardians of each child. Those parents/guardians who were able read and write signed the consent form themselves. Those who were unable to read and write provided their thumbprint after the information sheet and consent form was read to them. Children positive for IPs were treated at the health facilities according to national guidelines.

\section{Results}

Socio-demographic characteristics

A total of 158 children aged three to 59 months presenting with diarrhoea to the two health facilities participated in the study. Eighty-seven children (55.1\%) were from Adare Hospital and 71 (44.9\%) were from Millennium Health Centre. The majority of the children (70.3 \%) were aged below 24 months. Eighty-one children (51.3\%) were male. Figure 2 shows the distribution of ages and sex among the study participants.

The majority of children (91.1\%) were urban residents (residents of Hawassa) and the remaining $8.9 \%$ were residents of the surrounding rural kebeles (the smallest government administrative units in Ethiopia). Most children $(85.4 \%)$ had families with five members or less.

\section{Prevalence of intestinal parasites}

Of the total children who participated in this study, 42 (26.6\%) were positive for at least one IP species. In six children (3.8\%), double infection was detected. E. histolytica/dispar/moshkovskii was the most commonly encountered parasite (11.4\%), followed by G. duodenalis (7.0\%). Six children (3.8\%) were also positive for the Cryptosporidium species. Intestinal helminths were detected in 13 children (8.2\%). Ascaris lumbricoides (A. lumbricoides) 


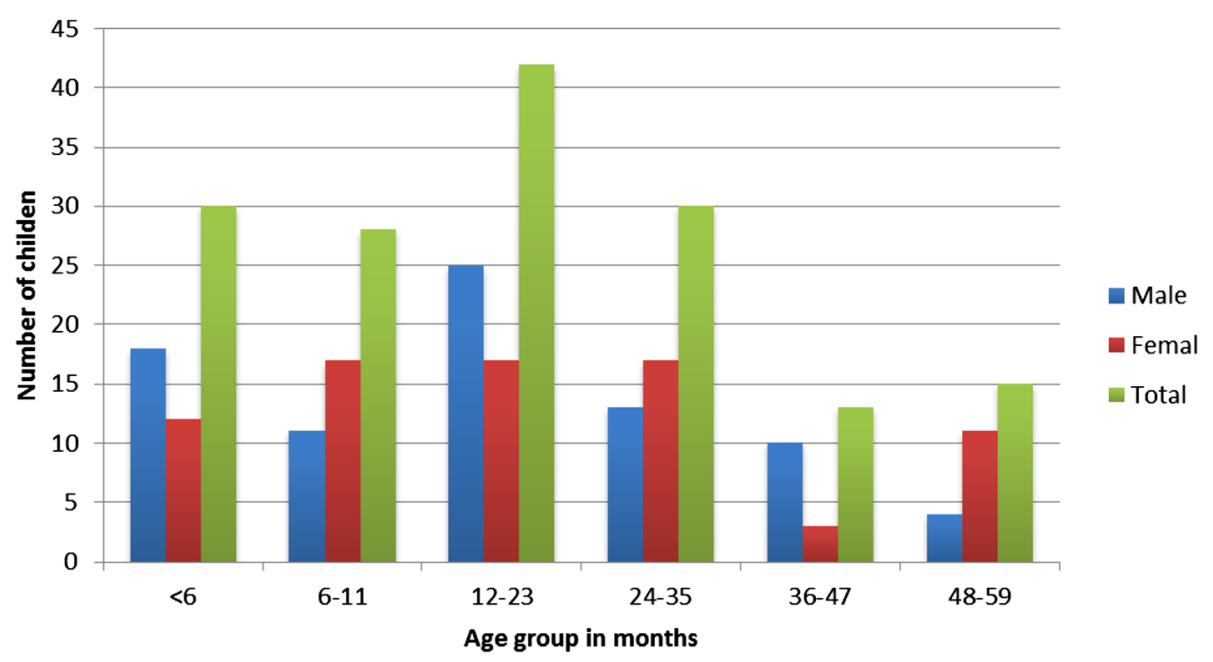

Fig. 2 Age and sex distribution of the study participants, Hawassa, 2011

and Hymenolepis nana (H. nana) were each detected in $3.8 \%$ of the children, while one child had Trichuris trichiura (T. trichiura). The prevalence rates of the IPs detected in this study are shown in Fig. 3.

According to the information given by the parents/ guardians, more than half of the children $(63.3 \%)$ had watery diarrhoea. The duration of diarrhoea in the majority of the children $(79.1 \%)$ was 1 to 5 days. Nearly a third (32.9\%) experienced vomiting.

The prevalence of each of the IPs isolated is presented in Table 1, categorised by age group. E. histolytica/ dispar/moshkovskii was detected in 5 (33\%) and 6 (20\%) children in the age groups 48-59 and 24-35 months, respectively. G. duodenalis and Cryptosporidium species were identified in two children and one child under 6 months of age, respectively.

\section{Factors associated with intestinal parasitic infections}

Factors associated with IPIs in the study participants are presented in Table 2. An almost equal proportion of male $(51.3 \%)$ and female $(48.7 \%)$ children participated in the study, with IP prevalence rates of 27.2 and $26 \%$,

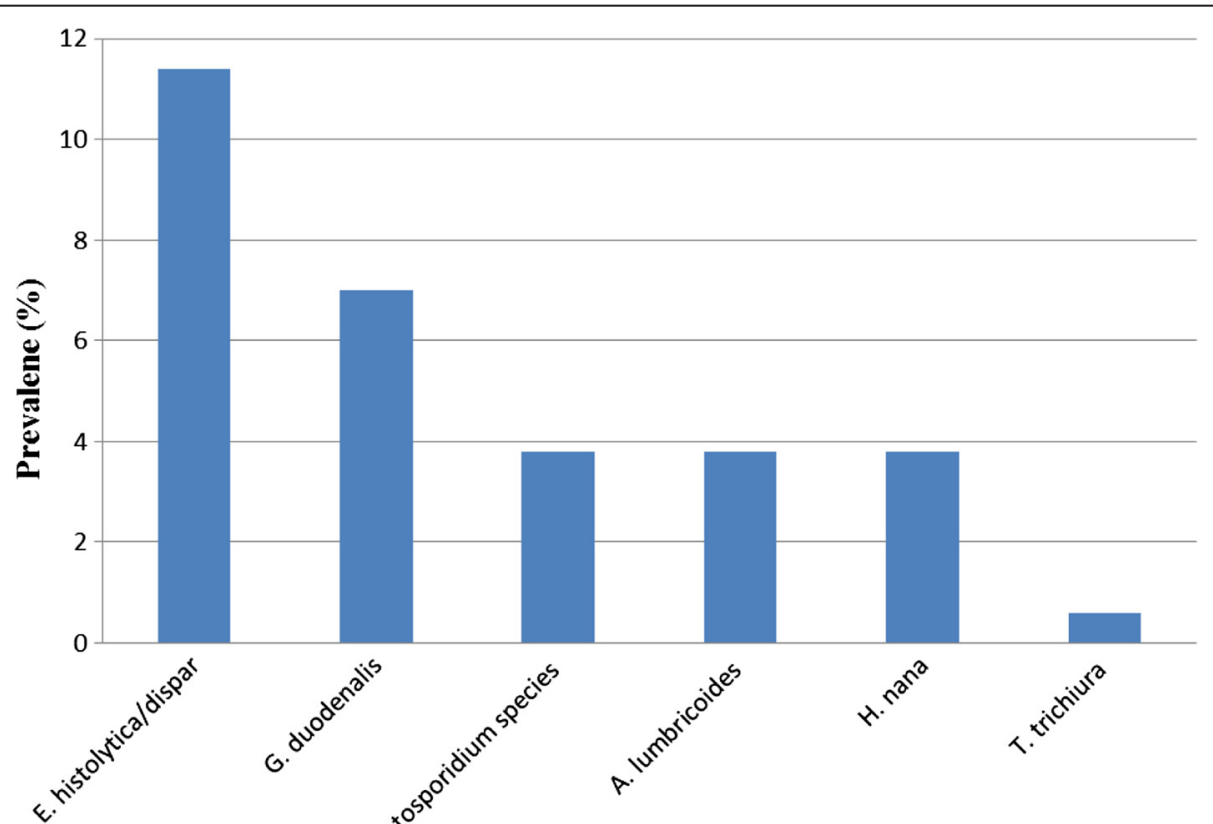

Parasite species

Fig. 3 Frequency of intestinal parasites identified among children under 5 years of age with diarrhoea in Hawassa, 2011 
Table 1 Distribution of intestinal parasite species by age group among children under 5 years of age with diarrhoeal diseases presenting to Adare Hospital and Millennium Health Centre, 2011, Hawassa, South Ethiopia

\begin{tabular}{|c|c|c|c|c|c|c|c|c|c|}
\hline \multirow[t]{3}{*}{ Age, in months } & \multicolumn{2}{|c|}{ E.histolytica/dispar/moshkovskii } & \multicolumn{2}{|c|}{ G. duodenalis } & \multicolumn{2}{|c|}{ Cryptosporidium species } & \multicolumn{2}{|c|}{ A. lumbricoides/H. nana/T. trichiura } & \multirow{3}{*}{$\begin{array}{l}\text { Total } \\
\text { n (\%) }\end{array}$} \\
\hline & Positive & Negative & Positive & $\overline{\text { Negative }}$ & Positive & Negative & Positive & Negative & \\
\hline & n (\%) & n (\%) & n (\%) & n (\%) & n (\%) & n (\%) & n (\%) & $\mathrm{n}(\%)$ & \\
\hline$<6$ & $0(0)$ & $30(100)$ & $2(7)$ & $28(93)$ & $1(3)$ & $29(97)$ & $0(0)$ & $30(100)$ & $30(19)$ \\
\hline $6-11$ & $2(7)$ & $26(93)$ & $0(0)$ & $28(100)$ & $0(0)$ & $28(100)$ & $2(7)$ & $26(93)$ & $28(18)$ \\
\hline $12-23$ & $3(7)$ & $39(93)$ & $1(2)$ & $41(98)$ & $0(0)$ & $42(100)$ & $2(5)$ & $40(95)$ & $42(27)$ \\
\hline $24-35$ & $6(20)$ & $24(80)$ & $4(13)$ & $26(87)$ & $2(7)$ & $28(93)$ & $3(10)$ & $27(90)$ & $30(19)$ \\
\hline $36-47$ & $2(15)$ & $11(85)$ & $2(15)$ & $11(85)$ & $0(0)$ & $13(100)$ & $4(31)$ & $9(69)$ & $13(8)$ \\
\hline $48-59$ & $5(33)$ & $10(67)$ & $2(13)$ & $13(87)$ & $3(20)$ & $12(80)$ & $2(13)$ & $13(87)$ & $15(9)$ \\
\hline Total & $18(11)$ & $140(89)$ & $11(7)$ & 147 (93) & $6(4)$ & $152(96)$ & $13(8)$ & $145(92)$ & $158(100)$ \\
\hline
\end{tabular}

respectively. No significant difference in prevalence of IPs according to gender was observed $(p>0.05)$.

The IP prevalence rate among children who were exclusively breastfed (EBF) (27.8\%) and those who were breastfed but also given complementary food (22.2 \%) at the point of data collection was 6.8 and $14.3 \%$, respectively. No significant difference was observed. The majority of the parents/guardians $(83.5 \%)$ were breastfeeding (EBF and breastfeeding with complementary food) their children at the point of data collection, and the remaining $16.5 \%$ had ceased breastfeeding. The prevalence rates of IPs among children who were being breastfed and those who were no longer being breastfed were $30(22.7 \%)$ and 12 (46.2\%), respectively. A significant difference in the prevalence of IPs among the children being breastfed and those who were no longer being breastfed was observed $(\mathrm{COR}=0.343,95 \% \mathrm{CI}$ : 0.124-0.821).

The prevalence of IPs among children aged $<24$ months (70.3\%) and aged $\geq 24$ months (29.7\%) was 18 (16.2\%) and 24 (51.1\%), respectively. A significant difference in the prevalence of IPs according to age group was observed $(\mathrm{COR}=0.185,95 \% \mathrm{CI}$ : 0.087-0.398). After adjusting for other variables (see Table 2), the multivariable analysis

Table 2 Univariate and multivariable analyses of factors associated with parasitic infections among children under 5 years of age with diarrhoeal diseases presenting to Adare Hospital and Millennium Health Centre, 2011, Hawassa, South Ethiopia

\begin{tabular}{|c|c|c|c|c|c|}
\hline \multirow[t]{3}{*}{ Characteristics } & & \multicolumn{2}{|c|}{ Intestinal parasites } & \multirow[t]{3}{*}{ COR $(95 \% \mathrm{Cl})$} & \multirow[t]{3}{*}{ AOR $(95 \% \mathrm{Cl})$} \\
\hline & & \multirow{2}{*}{$\begin{array}{l}\text { Positive } \\
\text { n (\%) }\end{array}$} & \multirow{2}{*}{$\begin{array}{l}\text { Negative } \\
\text { n (\%) }\end{array}$} & & \\
\hline & & & & & \\
\hline \multirow[t]{2}{*}{ Gender } & Female & $20(26.0)$ & $57(74.0)$ & 1 & 1 \\
\hline & Male & $22(27.2)$ & $59(72.8)$ & $1.063(0.524-2.154)$ & $0.560(0.233-1.344)$ \\
\hline \multirow[t]{2}{*}{ Age, in months } & $<24$ & $18(16.2)$ & $93(83.8)$ & 1 & 1 \\
\hline & $\geq 24$ & $24(51.1)$ & $23(48.9)$ & $0.185(0.087-0.398)^{*}$ & $0.221(0.085-0.576)^{*}$ \\
\hline \multirow[t]{2}{*}{ Residence } & Urban & $38(26.4)$ & $106(73.6)$ & & \\
\hline & Rural & $4(28.6)$ & $10(71.4)$ & $0.896(0.265-3.028)$ & $1.772(0.334-9.393)$ \\
\hline \multirow[t]{2}{*}{ Family size } & $<5$ & $34(25.2)$ & $101(74.8)$ & & \\
\hline & $\geq 5$ & $8(34.8)$ & $15(65.2)$ & $0.631(0.246-1.619)$ & $0.795(0.235-2.693)$ \\
\hline \multirow[t]{2}{*}{ Breastfeeding } & Yes & $30(27.7)$ & $102(77.3)$ & 1 & \\
\hline & No & $12(46.2)$ & $14(53.8)$ & $0.343(0.124-0.821)^{*}$ & $0.578(0.140-2.394)$ \\
\hline \multirow[t]{2}{*}{ Breastfeeding pattern } & EBF & $3(6.8)$ & $41(93.2)$ & 1 & 1 \\
\hline & $\begin{array}{l}\text { Breastfeeding with } \\
\text { complementary food }\end{array}$ & $5(14.3)$ & $30(85.7)$ & $1.170(0.518-2.643)$ & $1.360(0.55-3.366)$ \\
\hline \multirow[t]{2}{*}{ Complementary food initiated } & After 6th month & $27(29)$ & $66(71)$ & 1 & 1 \\
\hline & Before 6th month & 7 (33.3) & $14(66.7)$ & $0.801(0.271-2.369)$ & $0.778(0.234-2.589)$ \\
\hline \multirow[t]{2}{*}{ Contact with animals } & No & $33(24.4)$ & $101(75.6)$ & 1 & 1 \\
\hline & Yes & $9(37.5)$ & $15(62.5)$ & $1.836(0.735-4.585)$ & $0.728(0.253-2.098)$ \\
\hline
\end{tabular}


revealed that the age group $\geq 24$ months was a predictor of IPIs (AOR = 0.221, 95 \% CI: 0.085-0.576).

\section{Discussion}

The overall prevalence of IPIs in the study participants was $26.6 \%$, indicating that IPs are common in children with diarrhoeal diseases in the study area. Even though the causal relationship couldn't be established in this study, previous studies have shown that IPs are associated with diarrhoeal diseases $[2,19]$. Intestinal parasitic infections may also increase susceptibility to other gastrointestinal pathogens [20].

The prevalence of IPs found in this study is lower than the prevalence reported in other studies from Gondar (52.3\%) [21] and Jimma (65.8 \%) [22] in Ethiopia, and other countries such as Cameroon (59.2\%) and India $(46.5 \%)[23,24]$. On the other hand, the overall prevalence of IPs found in this study is slightly higher than findings from Mozambique (14.5\%), Nigeria (23.3\%) and Tanzania $(15.1 \%)[3,25,26]$. These variations could be due to differences in the age, hygiene practices and parental socio-economic status of the participants involved in these studies, as well as seasonal differences. A similar prevalence of IPs was reported in a study carried out in Addis Ababa (27.5 \%) [27].

The enteric protozoan pathogens E. histolytica, G. duodenalis and C. parvum are known to cause diarrhoea in children. In this study, E. histolytica/dispar/moshkovskii was the predominant IP isolated. Mondal et al. documented that children with $E$. histolytica-associated diarrhoeal illnesses are more likely to be malnourished and stunted [28]. Differentiations in the morphologically identical species of Entamoeba were not within the scope of this study, as only conventional microscopy was used to detect the amoebae. Earlier reports, however, have suggested that amebiasis was overdiagnosed in the absence of the pathogenic E. histolytica in adult patients in Ethiopia [29, 30].

In our study, G. duodenalis was the second most prevalent IP detected. Giardiasis is usually associated with poor sanitary conditions and insufficient water treatment. Nutritional deficiency is common in children symptomatically infected with Giardia [31]. Apart from its acute clinical symptoms, infection with G. duodenalis may result in cognitive deficit [32]. The Cryptosporidium species was detected in $3.8 \%$ of the children in this study, which is lower than the $8.1 \%$ prevalence reported among children with diarrhoea in Addis Ababa [27]. One Cryptosporidium and two Giardia infections were detected in infants under 6 months of age. Exposure to Cryptosporidium and Giardia in early childhood has also been reported elsewhere [33, 34].

Helminthic intestinal parasites, particularly STHs, commonly infect children in developing countries, including Ethiopia [10, 11]. In this study, helminthic infections were identified in 13 (8\%) of the children, with 7 (4.4\%) infected with the STHs A. lumbricoides and T. trichiura. The recently initiated national school-based deworming programme might have an impact on the STH infection rate among preschool children in the long run. On the other hand, as reduced efficacy of albendazole and mebendazole against $A$. lumbricoides and hookworms has been reported in Northwest Ethiopia [35], an assessment of the efficacy of anthelmintic drugs in the study area is urgently needed. Clinical symptoms signalling STH infections are related to worm burden [36]. However in this study, infection intensity was not determined. Moreover, as the single wet preparation technique was used to detect the parasites, the number of children infected with parasitic helminths could have been underestimated in this study.

In this study, 18 (16.2 \%) children aged below 24 months were positive for IPs, whereas the prevalence among those aged 24 months and above was $51.1 \%$. This difference is significant. The higher prevalence of IPs in children aged $\geq 24$ months as compared to children aged $<24$ months might be explained by the older children's contact with faecally-contaminated soil while playing, which could predispose them to IPs.

The prevalence of IPs among EBF children and children being breastfed but also receiving complementary food was similar in this study. Exclusive breastfeeding plays a significant role in protecting against common infectious agents during infancy, as well as preventing hospitalization for diarrhoea [37]. An earlier review also indicated the role of breastfeeding in protecting against diarrhoea incidence, prevalence, hospitalizations, diarrhoea mortality and all-cause mortality [38]. The small number of children included in this study could account for the contrary results pertaining to EBF obtained those children who were no longer being breastfed and those who were breastfed with complementary food constituted $72.2 \%$ of the total number of study participants. Of these, 21 (18.4\%) started to receive complementary food before the age of 6 months, while 93 (81.6\%) started at the sixth month, with IP isolation rates of 33.3 and $29 \%$, respectively. No significant difference in prevalence rates of IPs among children who started receiving complementary food before they turned 6 months and those who received it after was observed.

In this study, the majority of the children (91.1\%) were urban residents, and living in families with less than five members $(85.4 \%)$. No significant difference in the prevalence of IPs among children from urban areas $(26.4 \%)$ and rural areas (28.6 \%) was observed. Similarly, prevalence of IPs among children whose family had $<5$ members (25.2 \%) and those whose family had $\geq 5$ members $(34.8 \%)$ was also not significant. Other possible 
factors such as washing hands after defecation and whether a child wears shoes or not, and certain demographic factors of mothers, such as literacy and occupation, may affect infection of the child with IPs $[39,40]$. However, these factors were not assessed in this study.

The prevalence of IPs in children with a history of contact with animals $(15.2 \%)$ and those with no history of animal contact $(84.8 \%)$ was similar. Even though intestinal protozoan parasites detected in this study are of zoonotic importance [41, 42], a limitation of this study is that data on contact with specific animals was not generated. Moreover, it has been documented that some intestinal protozoan parasites may impair the nutritional status of children [43] and diarrhoea is among the major causes of death in children with severe malnutrition [44]. However, anthropometric parameters were not measured in this study.

\section{Conclusion}

The present study found that IPs cause diarrhoea in children under 5 years of age. Specifically, the study sheds light on the parasitic profile of children under 5 years of age with diarrhoeal diseases in Hawassa, South Ethiopia. Parasitological examinations should be considered and performed prior to empirical treatment of children under 5 years of age presenting with diarrhoea. Health information about how to prevent diarrheal diseases in general and IPIs in particular should be provided to parents of young children.

\section{Additional file}

Additional file 1: Multilingual abstracts in the six official working languages of the United Nations. (PDF $360 \mathrm{~kb}$ )

\section{Abbreviations}

EBF: Exclusively breastfed; IP: Intestinal parasite; IPI: Intestinal parasitic infection; SNNPR: Southern Nations, Nationalities and People's Region; STHs: Soil-transmitted helminths; WHO: World Health Organization.

\section{Competing interests}

The authors declare that they have no competing interests.

\section{Authors' contributions}

GM, GB and AZ conceived and designed the study. GM was involved in the data collection. GB and AZ supervised the data collection. GM and EZ were involved in the data analysis. EZ and SD drafted the paper. EZ critically reviewed the paper. All authors read and approved the final version of the paper for submission.

\section{Acknowledgements}

We thank Jimma University for funding this study. We are grateful to the administration and laboratory staff of the two health facilities included in this study for their support during data collection. We are also grateful to the study participants and their parents/guardians.

\section{Author details}

${ }^{1}$ Department of Medical Laboratory Technology, Hawassa College of Health Sciences, Hawassa, Ethiopia. ${ }^{2}$ Department of Medical Laboratory Sciences and Pathology, College of Health Sciences, Jimma University, Jimma, Ethiopia.

Received: 4 June 2015 Accepted: 26 October 2015

Published online: 04 November 2015

\section{References}

1. World Health Organization. Diarrhoeal disease fact sheet. Accessed 07 May 2014. Available at http://www.who.int/mediacentre/factsheets/fs330/en/.

2. UNICEF/WHO. Diarrhea: Why children are still dying and what can be done. New York: UNICEF/WHO; 2009.

3. Mandomando IM, Macete EV, Ruiz J, Sanz S, Abacassamo F, Vallès X, et al. Etiology of diarrhea in children younger than 5 years of age admitted in a rural hospital of Southern Mozambique. Am J Trop Med Hyg. 2007;76:522-7.

4. Sergio JV, de Leon Ponce AC. Analysis of mortality from diarrheic diseases in under-five children in Brazilian cities with more than 150,000 inhabitants. Cad Saude Publica. 2009;25:1093-102.

5. World Gastroenterology Organisation (WGO). World Gastroenterology Organisation global guidelines: acute diarrhea in adults and children: a global perspective. Milwaukee: WGO; 2012.

6. Abera A, Nibret E. Prevalence of gastrointestinal helminthic infections and associated risk factors among schoolchildren in Tilili town, northwest Ethiopia. Asian Pac J Trop Med. 2014;7:525-30.

7. Mathewos B, Alemu A, Woldeyohannes D, Alemu A, Addis Z, Tiruneh M, et al. Current status of soil transmitted helminths and Schistosoma mansoni infection among children in two primary schools in North Gondar, Northwest Ethiopia: a cross sectional study. BMC Res Notes. 2014;7:88.

8. Getaneh A, Medhin G, Shimelis T. Cryptosporidium and Strongyloides stercoralis infections among people with and without HIV infection and efficiency of diagnostic methods for Strongyloides in Yirgalem Hospital, southern Ethiopia. BMC Res Notes. 2010;3:90.

9. Alemu A, Atnafu A, Addis Z, Shiferaw Y, Teklu T, Mathewos B, et al. Soil transmitted helminths and Schistosoma mansoni infections among school children in zarima town, northwest Ethiopia. BMC Infect Dis. 2011;11:189.

10. Jejaw A, Zemene E, Alemu Y, Mengistie Z. High prevalence of Schistosoma mansoni and other intestinal parasites among elementary school children in Southwest Ethiopia: a cross-sectional study. BMC Public Health. 2015;15:600.

11. Dana D, Mekonnen Z, Emana D, Ayana M, Getachew M, Workneh N, et al. Prevalence and intensity of soil-transmitted helminth infections among pre-school age children in 12 kindergartens in Jimma Town, southwest Ethiopia. Trans R Soc Trop Med Hyg. 2015;109:225-7.

12. Federal Democratic Republic of Ethiopia. National Hygiene and Sanitation Strategy Ministry of Health. December 2005.

13. Ethiopia Demographic and health Survey (EDHS) 2011. Central Statistical Agency, Addis Ababa, Ethiopia, ICF International Calverton, Maryland, USA 2012.

14. Mulatu G, Beyene G, Zeynudin A. Prevalence of Shigella, salmonella and campylobacter species and their susceptibility patters among under five children with diarrhea in hawassa town, South Ethiopia. Ethiop J Health Sci. 2014;24:101-8

15. Abu-Elyazeed RR, Wierzba TF, Frenck RW, Putnam SD, Rao MR, Savarino SJ, et al. Epidemiology of Shigella-associated diarrhea in rural Egyptian children. Am J Trop Med Hyg. 2004;71:367-72.

16. von Seidlein L, Kim DR, Ali M, Lee H, Wang X, Thiem VD, et al. A multicentre study of Shigella diarrhoea in six Asian countries: Disease burden, clinical manifestations, and microbiology. PLoS Med. 2006;3:e353.

17. Jiao BX, Wang HZ, Liu Y, Li J, Guo J, Li M, et al. Clinical feature of Cryptosporidium infection in HIV/AIDS patients with chronic diarrhea. Zhonghua Yi Xue Za Zhi. 2011;91:2611-4.

18. Cheesbrough M. Medical laboratory manual for tropical countries, vol. 1. 2nd ed. UK: Cambridge press; 2006. p. 292-08.

19. Manrique-Abril FG, Tigne y Diane B, Bello SE, Ospina JM. Diarrhoea-causing agents in children aged less than five in Tunja, Colombia. Rev Salud Publica (Bogota). 2006:8:88-97.

20. Su C, Cao Y, Zhang M, Kaplan J, Su L, Fu Y, et al. Helminth infection impairs autophagy-mediated killing of bacterial enteropathogens by macrophages. J Immunol. 2012;189:1459-66.

21. Mitikie G, Kassu A, Genetu A, Nigussie D. Campylobacter enteritis among children in Dembia district, northwest Ethiopia. East Afr Med J. 2000;77:654-7. 
22. Beyene G, Haile-Amlak A. Antimicrobial sensitivity Pattern of Campylobacter species among children in Jimma University Specialized Hospital, Southwest Ethiopia. Ethiop J Health Dev. 2004;18:185-9.

23. Yongsi HBN. Pathogenic microorganisms associated with childhood diarrhea in Low-and-middle income countries: Case study of Yaoundé Cameroon. Int J Environ Res Public Health. 2008;5:213-29.

24. Kaur R, Rawat D, Kakkar M, Uppal B, Sharma VK. Intestinal parasites in children with Diarrhea in Delhi, India. Southeast Asian J Trop Med Public Health. 2002;33:725-9.

25. Tinuade O, John O, Saheed O, Oyeku O, Fidelis N, Olabisi D. Parasitic etiology of childhood diarrhea. Indian J Pediatr. 2006;73:1081-4.

26. Vargas M, Gascon J, Casals C, Schellenberg D, Urassa H, Kahigwa E, et al. Etiology of diarrhea in children less than five years of age in ifakara, Tanzania. Am J Trop Med Hyg. 2004;70:536-9.

27. Adamu H, Endeshaw T, Teka T, Kifle A, Petrose B. The prevalence of Intestinal parasites in paediatric diarrhoeal and non-diarrhoeal patients in Addis Ababa hospitals. Ethiop J Health Dev. 2005;20:39-46.

28. Mondal D, Petri WA, Sack RB, Kirkpatrick BD, Haque R. Entamoeba histolyticaassociated diarrheal illness is negatively associated with the growth of preschool children: evidence from a prospective study. Trans R Soc Trop Med Hyg. 2006;100:1032-8.

29. Kebede A, Verweij J, Dorigo-Zetsma W, Sanders E, Messele T, van Lieshout L, et al. Overdiagnosis of amoebiasis in the absence of Entamoeba histolytica among patients presenting with diarrhoea in Wonji and Akaki, Ethiopia. Trans R Soc Trop Med Hyg. 2003;97:305-7.

30. Gebertsadik A, Kebede A, Mezemer M, Tasew G. Detection and differentiation of two morphologically identical species of Entamoeba. Ethiop J Health Dev. 2004;18:121-4.

31. Newman RD, Moore SR, Lima AA, Nataro JP, Guerrant RL, Sears CL. A longitudinal study of Giardia lamblia infection in north-east Brazilian children. Trop Med Int Health. 2001;6:624-34.

32. Halliez MC. Extra-intestinal and long term consequences of Giardia duodenalis infections. World J Gastroenterol. 2013;19:8974.

33. Robin G, Fraser D, Orr N, Sela T, Slepon R, Ambar R, et al. Cryptosporidium Infection in Bedouin Infants Assessed by Prospective Evaluation of Anticryptosporidial Antibodies and Stool Examination. Am J Epidemiol. 2001;153:194-201.

34. Fraser D, Bilenko N, Deckelbaum R, Dagan R, El-On J, Naggan L. Giardia lamblia carriage in Israeli Bedouin infants: Risk factors and consequences. CID. 2000;30:419-24.

35. Adugna S, Kebede Y, Moges F, Tiruneh M. Efficacy of mebendazole and albendazole for Ascaris lumbricoides and hookworm infections in an area with long time exposure for antihelminthes, Northwest Ethiopia. Ethiop Med J. 2007:45:301-6.

36. Pullan RL, Smith JL, Jasrasaria R, Brooker SJ. Global numbers of infection and disease burden of soil transmitted helminth infections in 2010. Parasites \& Vectors. 2014;7:37.

37. Quigley MA, Kelly YJ, Sacker A. Breastfeeding and Hospitalization for Diarrheal and Respiratory Infection in the United Kingdom Millennium Cohort Study. Pediatrics. 2007;119:e837-42.

38. Lamberti LM, Fischer Walker CL, Noiman A, Victora C, Black RE. Breastfeeding and the risk for diarrhea morbidity and mortality. BMC Public Health. 2011;11 Suppl 3:S15.

39. Okyay P, Ertug S, Gultekin B, Onen O, Beser E. Intestinal parasites prevalence and related factors in school children, a western city sample-Turkey. BMC Public Health. 2004;4:64.

40. Tadesse $\mathrm{G}$. The prevalence of intestinal helminthic infections and associated risk factors among school children in Babile town, eastern Ethiopia. Ethiop J Health Dev. 2005;19:140-7.

41. Mak JW. Important zoonotic intestinal protozoan parasites in Asia. Trop Biomed. 2004;21:39-50

42. Zhao GH, Du SZ, Wang HB, Hu XF, Deng MJ, Yu SK, et al. First report of zoonotic Cryptosporidium spp., Giardia intestinalis and Enterocytozoon bieneusi in golden takins (Budorcas taxicolor bedfordi). Infect Genet Evol. 2015;34:394-401.

43. Boeke CE, Mora-Plazas M, Forero Y, Villamor E. Intestinal protozoan infections in relation to nutritional status and gastrointestinal morbidity in Colombian school children. J Trop Pediatr. 2010;56:299-306.

44. Irena A, Mwambazi M, Mulenga V. Diarrhea is a major killer of children with severe acute malnutrition admitted to inpatient set-up in Lusaka, Zambia. Nutr J. 2011;10:110

\section{Submit your next manuscript to BioMed Central and take full advantage of:}

- Convenient online submission

- Thorough peer review

- No space constraints or color figure charges

- Immediate publication on acceptance

- Inclusion in PubMed, CAS, Scopus and Google Scholar

- Research which is freely available for redistribution 